\title{
The Design Strategy Analysis of A Green Healthy Residence
}

\author{
Qiliang YU \\ School of Construction and Environment Engineering \\ Shenzhen Polytechnic \\ Shenzhen, Guangdong 518055, China \\ E-mail: smarta@ szpt.edu.cn
}

\author{
Binquan ZHANG \\ School of Construction and Environment Engineering \\ Shenzhen Polytechnic \\ Shenzhen, Guangdong 518055, China \\ E-mail: zbq@ szpt.edu.cn
}

\begin{abstract}
This paper takes Urumqi Xiucheng Estate as an example to analyze the health concept of architectural design based on the proposed green building design and corresponding technology, in order to promote the application of the concept of green healthy residential planning and design. The project was assessed in $\mathbf{2 0 1 3}$ as the country's fifty-seventh health residential demonstration (first one in Xinjiang) and awarded as the three star green building.
\end{abstract}

Keywords-green building; low carbon; intelligent residential

\section{PRoject Overview}

The project is located in Xinjiang Urumqi, with a total construction land area of 56,063 square meters, a total floor area of 151,370 square meters, of which the residential floor area is 141,357 square meters, the project intends to create an integrated region of business, catering and living in a bustling city streets.

The design idea of project advocates healthy and natural, focus on "green, healthy, intelligent" innovation focus on design, adopts of a series of green building technology and realizes the habitable indoor thermal environment, the application of health residential technology, to create a comfortable indoor space environment and realize the intelligent way of life. The project will implement the spirit of the green healthy life, cycle concept, design technology and products of green residential health in the planning, design, equipment procurement and construction process to build real green healthy residential. The project was assessed in 2013 as the country's fifty-seventh health residential demonstration (first one in Xinjiang) and awarded as the three star green building. This paper summarizes the project on the implementation of green health residential goals, design strategies and techniques.

\section{Healthy Residential ENVIRONMENT BUILDING AND PLANNING}

\section{A. Base Location and Pollution Source Control}

The base was originally a wasteland, relatively flat, suitable for healthy living. No pollution sources exist in the base and the surrounding. After professional testing, site of the project is proved out of flooding, debris flow, seismic activity, electromagnetic radiation, toxic substances and dangerous source.

\section{B. The Combination of The Residential and Urban Space}

Residential products are designed with elements suitable for the requirements of the Xinjiang area, and is planned to form a suitable enclosed private space. Residential buildings are grouped with high and low blocks, effectively reducing the sense of uneasiness and oppression. Dotted blocks form good sight corridors, enhancing the integration with the whole urban space (Fig. 1).

The project is divided into three partitions by two city roads, and with residential areas concentrated on the southern land. Each partition has a good road system, giving full consideration for the separation of people and vehicles. Vehicle main entrance entrance for people are in the in the north and south respectively, to ensure efficient use of road interface. The residential area and urban space are organically combined, forming a convenient transportation network. Along the street is for business and is opened for public. Commercial interface and green space forms a rich change of urban commercial space. Invisible iron bars netted in high green fence to form a transparent interface between the residential area and the city with a soft landscape creating a vivid city space.

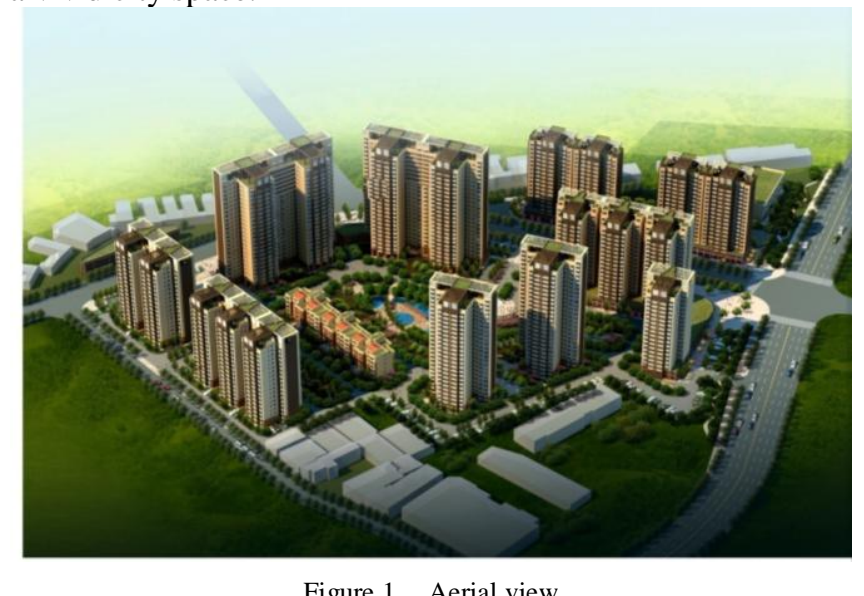

\section{Static and Dynamic Traffic Design}

Dynamic traffic design separates peoples from vehicles. The roads are classified clearly, smooth without overlapping and are efficiently but speed limited to reduce the interference to inhabitants as far as possible.

Main entrance are plotted on the road along with the north and south layout, the pedestrian entrances are plotted in 
central. At the entrance peoples and vehicles are separated, and the fire lanes are planed along the periphery. No vehicle appears in the residential garden. Each building meets fireman truck moving and ambulance needs. The barrier free walking path runs through every building, accompanying the landscape organically. Bicycle storage space is set up, providing convenience for residents to park nearby.

Motor vehicle parking spaces are arranged in an appropriate proportion between the basement and outside parking area to supply parking. The entrance of the garage and the main lane of the residential area is arranged smoothly, avoiding impairment to the living environment and to landscape environment.

\section{Residential Area Air Quality Control}

The base has a unique natural advantage and good air. Good base position ensured a good base of natural environment and air quality. The buildings are designed with open aisle, open elevator hall and open public activity platform, to ensure the internal ventilation. In landscape design lots of plants suitable for the local environment are selected for reasonable allocation and can effectively improve the living environment of the micro-climate and air quality.

For natural ventilation, fixed shutters are arranged on the bathroom door lower part. Bedroom, living room, kitchen have windows directly to the open air, and the window size is not less than $1 / 7$ of the room floor area; ventilation openings at the residential area are not less than $5 \%$ of the area of the floor.

The indoor fresh air system is a two-way flow with function of sterilization, dust collection, humidity adjustment and energy recovery, ensuring air quality in good condition for residents. Walls are equipped with a special air intake device, keeping indoor air circulation. (Fig. 2)

\section{THERMAL ENVIRONMENT DESIGN TECHNOLOGY}

\section{A. Reducing the Heat Island Effect}

By simulating the temperature range of each building in different time periods, it is shown that the maximum intensity of heat island intensity is at 14 o'clock in the whole day. The outdoor average temperature is about 32 degrees Celsius in this garden, the temperature is 31.4 degrees Celsius out of this garden. That is, in a typical summer day in the area, the average outdoor day heat island intensity is 0.6 degrees Celsius, meeting the requirements in "technical regulation of healthy residential construction". (Fig. 3)

The central dust collection system, which is set in each house, not only ensures the quality of the indoor air, but also avoids the second pollution to the household. (Fig. 4)

The layout is conducive to the summer leading wind direction, and building density is reasonable controlled, in order to provide good ventilation environment. Increasing the area of green plants, reasonable configuration, enhanced green shading effect and setting water landscape for residential area, reduces the temperature and improve the residential micro-climate. (Fig. 5) Pavement with penetrable tiles, keeps groundwater and improves the residential micro- circulation. The limits of motor vehicles to pass, reduces the exhaust emissions of motor vehicles. By using various reasonable design energy efficiency equipment, emissions of heat is reduced.

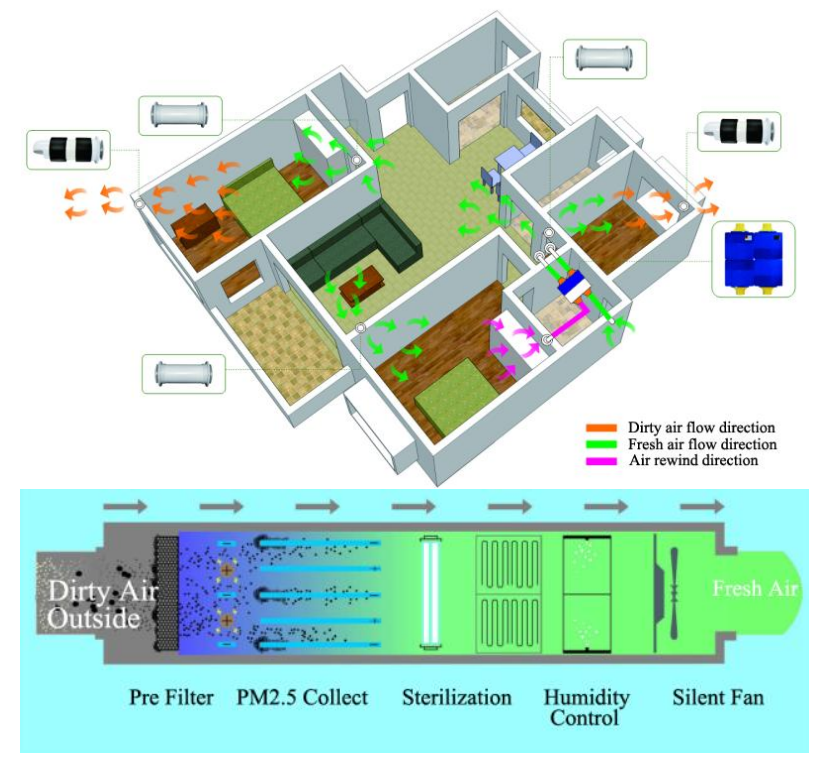

Figure 2. Two way flow of fresh air system

\section{B. Indoor Thermal Environment and Heating-Cooling System}

In the summer, fresh air system is installed to ensure a suitable times of indoor ventilation. An energy-saving heating equipment is installed for winter. Suite design is ensured for good ventilation, indoor temperature, humidity and air velocity. The thermal parameters meet comfort requirement for indoor thermal environment.

High efficiency fresh air system is hanged in the bathroom ceiling, and the outdoor machine with module for refrigeration system match the architectural style.

Heating system uses both wall mounted boiler heating and floor radiant heating, and with the using of new type, environmental pollution and energy waste are reduced.

\section{Building Structure Energy Saving Measures}

The project is located in a deep cold area. After calculation of energy conservation, $250 \mathrm{~mm}$ thickness aerated concrete block is used for the external wall on 1st---4th floor, and above the 4th floor $200 \mathrm{~mm}$ thickness aerated concrete block is used. $100 \mathrm{~mm}$ thickness rockwool and phenolic building board is used on first floor for exterior insulation, and $100 \mathrm{~mm}$ thickness extruded polystyrene board is installed above 2nd floor as exterior walls to isolating energy transmission between outdoor air and the interior, saving $60 \%$ of energy, fully meeting the requirements of building energy saving. The roof is made of $150 \mathrm{~mm}$ extruded polystyrene board, for the construction of thermal insulation. The 4+9+4+9+4 65 series Aluminum window with energytransform-bridge-break construct is used, made up with four cavity and three glass. The building roof is designed with 
shade frame and a solar panel is installed on the frame which can effectively shade the building and ensure the maximum area of solar panels.

\section{Renewable Energy Utilization}

This project uses solar energy as the heat source of the hot water. All buildings are equipped with centralized hot water system to supply hot water for all units. Auxiliary heat source beside solar energy is air-source heat pump to let the water temperature reach 55 degree. The solar collector is allglass vacuum tube type. The indoor hot water pipe system is partitioned as the cold water pipe system used.

\section{SOUND ENVIRONMENT DESIGN}

\section{A. Residential Area Noise Prevention Planning}

An overhead railway exists on the eastern side of this estate above 150 meters away. Noise barrier will be built by local government and a green tree belt with a width of about 40 meters between the residential area and the railway is developed to reduce the influence of noise.

The Residential planning includes business household along the street to effectively separate residential from commercial layout, reducing noise interference. In the residential area no motor vehicle will appear in the garden, peoples and vehicles are separated, along the road green tree belt will be set up to isolate noise. The water pump rooms, Emergency power generator rooms are placed at the southwest corner of the project site, other equipment and water supply rooms are set in the basement to reduce noise, and noise isolation cushion is installed under equipment foundations.

The large scale enclosure layout of the residential buildings effectively increases the distance between the buildings, which is conducive to reducing the mutual interference of the noise.

\section{B. Residential Anti Noise Design}

The elevator is not adjacent to the living room and bedroom. Indoor activity partition and quiet partition are set in different division to avoid noise interference. The sewer pipe is arranged as far as possible from the bedroom wall, and a pipeline will be packaged using noise-isolation material. When the water, heating and electrical pipes pass through the floor and wall, the sealing and sound insulation measures should be adopted. All gaps between the pipes and the wall or floor must be tightly sealed no matter socket used or not.

\section{Residential Indoor Sound Insulation}

Household wall uses $200 \mathrm{~mm}$ thick aerated concrete block up to top. Indoor partitions wall uses $100 \mathrm{~mm}$ thick aerated concrete block up to top. Floor uses the $120 \mathrm{~mm}$ thick reinforced concrete, and the using of floor radiant heating method makes a good solution to the problem of sound insulation between the upper and lower households. The windows sound insulation performance reaches $35 \mathrm{~dB}$, and with good performance of anti-theft door.

\section{Sound Insulation and Noise Reduction}

All equipment in the project are selected according to high-quality of silence standard, such as sanitary equipment, water supply and drainage pipeline, exhaust air exhaust device and others.

Water supply pumps, fire pumps are installed micro soundproofing check valves and flexible rubber joints.

Water pump, fan and other foundations are set vibration insulator. Water pumps, fans, air conditioners, such as the import and export of soft take over, are installed flexible joints which can reduce the vibration to the whole building.

Flexible lifts are installed to reduce vibration and noise, and using low speed pump as hot water heat pump reduces noise further.

The power generator is with a silencing equipment and noise-proofing room, according to the requirement of the use of sound insulation and sound processing by professional companies.

Special attention will be paid on the junctions and gaps of floors, walls, doors and so on, in order to ensure the sound insulation ability.

\section{Light ENVIRONMENT DESIGN}

Kitchens and washrooms are all with open windows for direct ventilation and lighting. Apartment layouts are designed with small depth, fully meeting the needs of all room lighting. Enclosed type of block layout increase the distance between all buildings to ensure enough sun lighting into windows, therefore landscape and interior lighting is very good in this project.

Outdoor night landscape lighting is arranged to avoid impacts to residents. To prevent dazzling to pedestrians no motor vehicles will appear in the garden.

Solar panels are using non reflective materials to avoid or reduce sunlight reflect by solar panels on low roof to above floors.

\section{CONCLUSION}

Urumqi Xiucheng project is a modeled healthy residential project. It meets the requirements of the three-star green building design standards, using green building technologies, such as the central dust removal system, solar hot water technology, water comprehensive utilization technology, household air technology, intelligent home furnishing, which plays a positive role in promoting the realization of green healthy residential. By using a lot of green technology, residential healthy project does not mean cost increasing, and does not mean the using of all new products blindly, but means a limited cost increasing and taking effective green technologies to improve the residential health, comfort, building the whole life cycle, and maximally saving resources. This green and healthy residential design technology has a strong demonstration effect and the future it will set a benchmark in domestic residential market.

\section{REFERENCE}

[1] Xue Feng. "Integrated technology solution for green low carbon residential building", Journal of architecture, vol. 286, Oct. 2013, pp. 68-75. 
[2] Sun Fengming, Tian Liang, Guo Xiaoying. "The green energy saving design of a small city living area", Industrial building, vol. 743, Mar. 2013, pp. 43-47.
[3] Feng Juan. "Energy saving building residential healthy - Shenyang riverside Metro", Journal of architecture design, Nov. 2008, pp 264268.

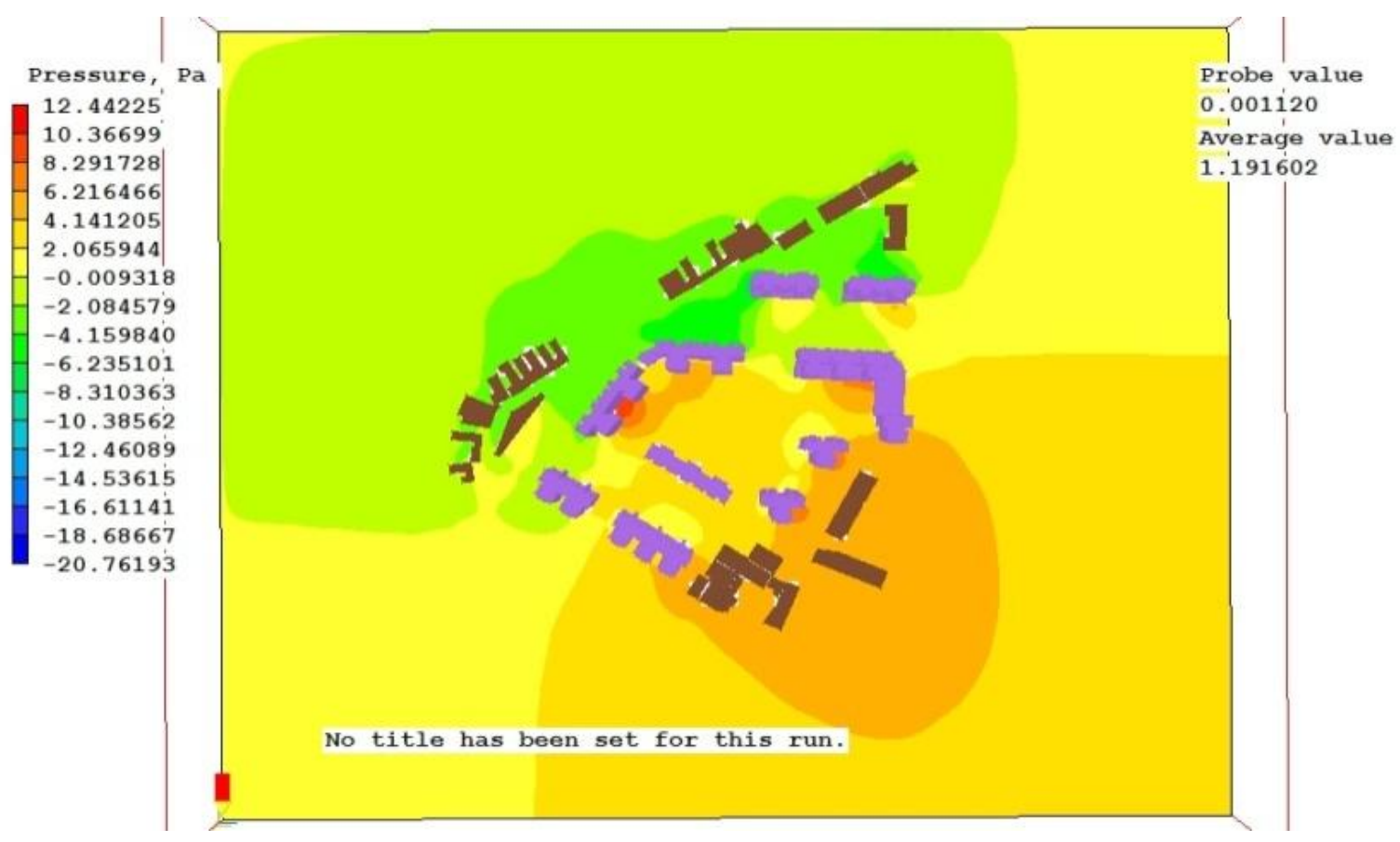

Figure 3. Analysis of heat island intensity

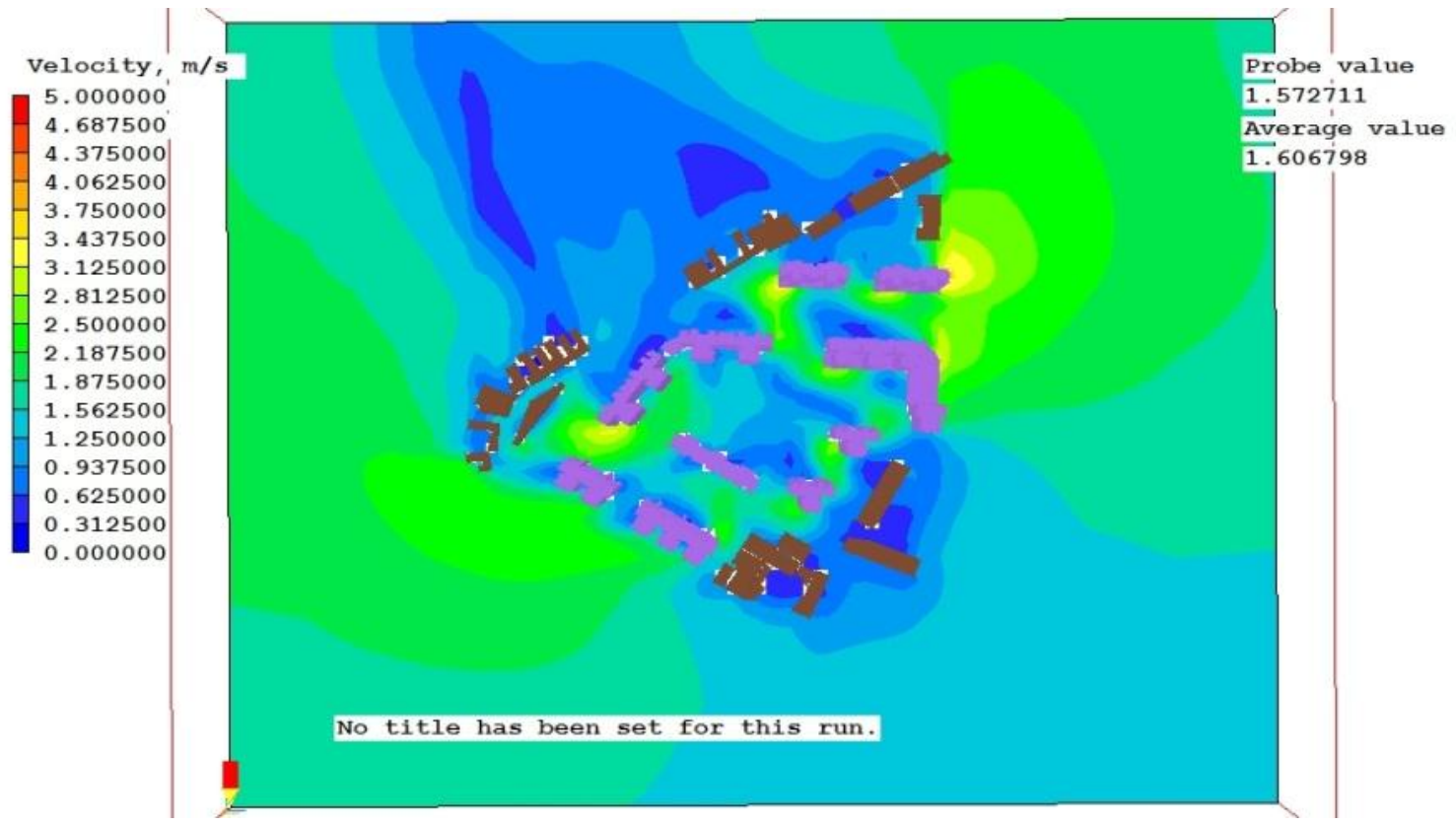

Figure 4. Analysis of air velocity 


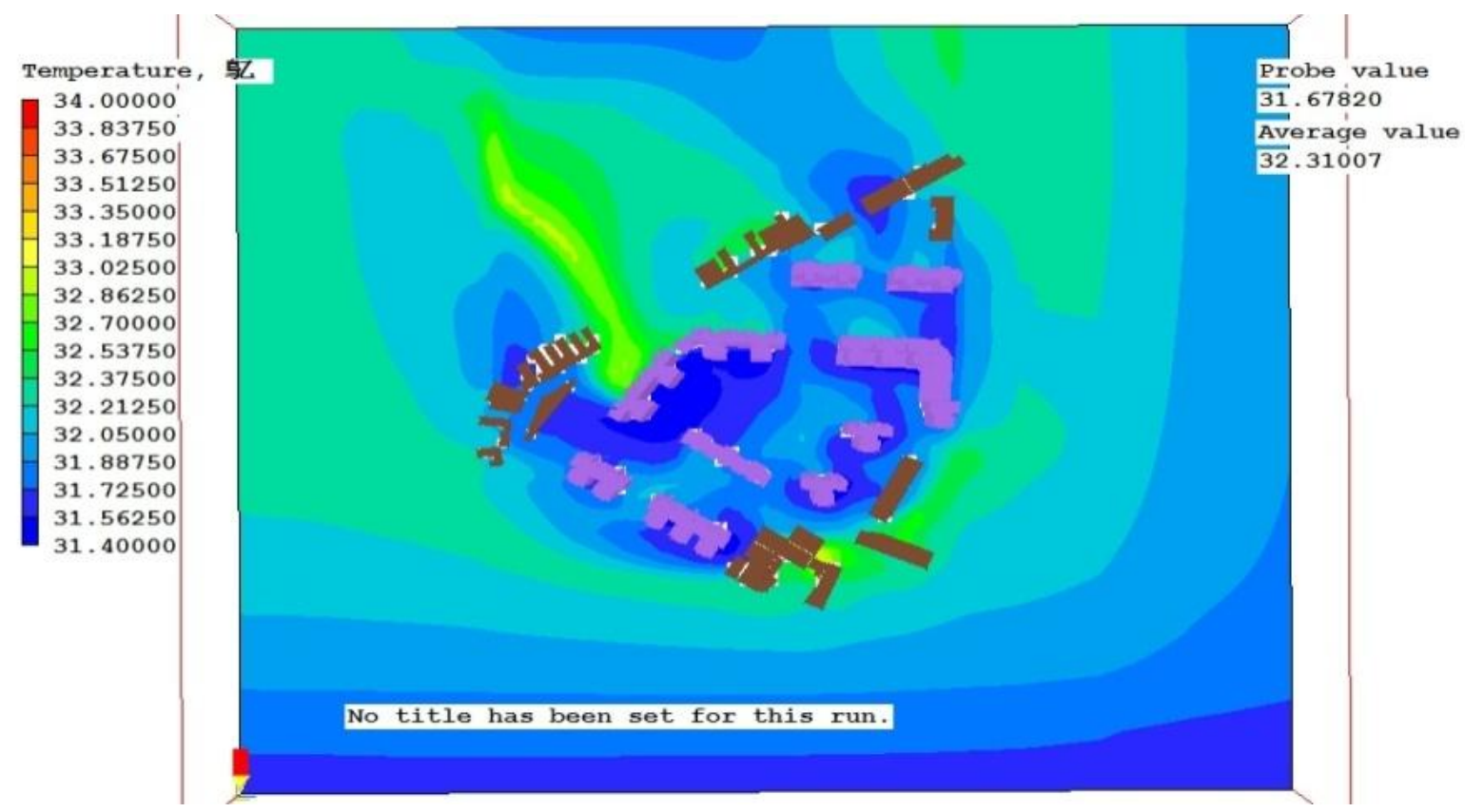

Figure 5. Analysis of temperature 